\title{
Association between inflammatory status and intima-media-thickness in children with juvenile idiopathic arthritis: preliminary data
}

\author{
L Breda*, D Di Marzio, A Scarinci, M Nozzi, K Falasca and F Chiarelli
}

Address: University of Chieti, Chieti, Italy

* Corresponding author

\author{
from $15^{\text {th }}$ Paediatric Rheumatology European Society (PreS) Congress \\ London, UK. 14-17 September 2008 \\ Published: 15 September 2008 \\ Pediatric Rheumatology 2008, 6(SuppI I):P59 doi:I0.I I86/I546-0096-6-SI-P59
}

This abstract is available from: http://www.ped-rheum.com/content/6/SI/P59

(C) 2008 Breda et al; licensee BioMed Central Ltd.

\section{Background}

Atherosclerosis as a cardiovascular disease has been found even in fetal period. However, information about risk factors of pre-clinical atherosclerosis in childhood has been limited [1].

Studies in childhood showed higher intima-media thickness (IMT) in children with chronic diseases such as type 1 diabetes [2], while no data are reported about juvenile idiopathic arthritis (JIA).

Hence, this study was aimed to find out signs of atherosclerosis and the relationship with markers of systemic inflammation in children with JIA.

\section{Materials and methods}

Carotid IMT was measured using high-resolution B-mode ultrasound in 21 JIA prepubertal children $(8 \mathrm{M} / 13 \mathrm{~F}$, mean age $8 \pm 2$ and mean duration of illness of 2 yrs), and 9 age- and sex-matched healthy controls. Erytrocyte sedimentation rate (ESR) and C-reactive protein (CRP) were used to measure systemic inflammation. Lipid profile was assessed in all patients.

\section{Results}

JIA children had an increased IMT $(\mathrm{p}=0.008)$ compared to healthy subjects; they also had higher levels of ESR and CRP ( $\mathrm{p}=0.001$ and $\mathrm{p}=0.05$ respectively).
No statistically significant differences between left and right carotid artery IMT were found ( $p>0.05)$.

There were no significant correlation between IMT and markers of systemic inflammation or lipid levels probably due to the small sample size of this preliminary investigation.

\section{Conclusion}

Children with JIA have increased carotid artery IMT indicating the presence of early carotid structural changes. This is consistent with hypotheses of a role to systemic inflammation in the pathogenesis of atherosclerosis in children. More data are needed to confirm our results.

\section{References}

I. Xiao-zheng Yahg, Ying Liu, Jie Mi, Chao-shu Tang, Jun-bao DU: Preclinical atherosclerosis evaluated by carotid artery intimamedia thickness and the risk factors in children. Chin Med J 2007, I 20:359-362.

2. Schwab KO, Krebs A, Krebs K, Schorb E, Hallermann K, SupertiFurga A, Zieger B, Marz W, Schmidt-Trucksass A, Winkler K: Early atherosclerosis in childhood type I diabetes: role of raised systolic blood pressure in the absence of dyslipidaemia. Eur J Pediatr 2007, 166:54|-8. 